\section{Impact of acute geriatric services for nursing home residents on emergency department presentation and hospitalisation}

\author{
Seo Lung Ling ${ }^{1}$, MBChB, MBBS FRACP, Chia-Ti Cheng ${ }^{2}$, MBChB, FRACP, Frank \\ Liu $^{2}$, MBBS FRACP, Deni Irwanto ${ }^{2}$, MBBS FRACP, Friedbert Kohler ${ }^{3,5}$, MBBS, \\ FAFRM, Matthew J Smith ${ }^{4}$, MBBS FACEM, Daniel KY Chan ${ }^{2,5,6}$, MD MBBS, FRACP
}

\begin{abstract}
Background. Prior to May 2015, our hospital provided only non-urgent geriatric services for nursing home residents. Thereafter, the Connecting Care Programme was introduced to provide acute geriatric services, including administration of intravenous antibiotics and fluids and a variety of other procedures. This audit aimed to investigate the impact of acute geriatric services for nursing home residents on emergency department presentation and hospitalisation.

Methods. Medical records of nursing home residents who presented to the Bankstown-Lidcombe Hospital before (from May to August 2014) and after (from May to August 2015) the Connecting Care Programme were retrospectively reviewed. The two groups were compared in terms of emergency department presentation and discharge rates.

Results. Respectively for the group before and after the programme, of all presentations to the emergency department, 276 and 318 involved nursing home residents (6.1\% vs 7.1\%, p=0.056). Of these, 106 and 167 were discharged from the emergency department (38.4\% vs $52.5 \%$, odds ratio $=1.76,95 \%$ confidence interval $=1.2-2.4, p=0.0008)$. The Connecting Care Programme increased the discharge rate in those with a diagnosis of fall without fracture $(70 \%$ vs $88 \%, \mathrm{p}=0.021)$, respiratory ( $11 \%$ vs $31 \%, \mathrm{p}=0.020$ ), gastrointestinal ( $34 \%$ vs $50 \%, \mathrm{p}=0.025)$, or cardiovascular ( $24 \%$ vs $60 \%$, p $=0.010)$ complaints.
\end{abstract}

Conclusion. The Connecting Care Programme resulted in an increased discharge rate and decreased hospital admission rate for nursing home residents who presented with fall without fracture, respiratory, gastrointestinal, or cardiovascular complaints. The programme may enable better utilisation of healthcare resources.

Key words: Emergency service, hospital; Health services for the aged

\section{ORIGINAL ARTICLE}

Department of Aged Care, St George Hospital, Kogarah, NSW, Australia

Department of Aged Care \&

Rehabilitation, Bankstown-Lidcombe Hospital, Bankstown, NSW, Australia

3 Department of Rehabilitation Medicine, Braeside, Liverpool \& Fairfield Hospitals, Prairiewood, NSW, Australia

4 Emergency Department, BankstownLidcombe Hospital, Bankstown, NSW, Australia

5 Faculty of Medicine, University of New South Wales, Sydney, NSW, Australia

Ingham Institute of Applied Medical Research, Liverpool, NSW, Australia
Correspondence to: Prof Daniel KY Chan, Department of Aged Care \& Rehabilitation, Bankstown-Lidcombe Hospital, Bankstown, NSW 2200, Australia.

Email:Daniel.Chan@sswahs.nsw.gov.au

\section{INTRODUCTION}

In Australia in 2015, about 270,559 people aged $\geq 65$ years were residents of residential care facility, and most of whom required high-level care. ${ }^{1}$ They are usually frail with multiple chronic diseases and have dementia. ${ }^{2}$ They frequently present to the emergency department and need hospitalisation. ${ }^{3}$ However, most of such presentations and subsequent 
hospitalisations can be avoided, ${ }^{4}$ especially if alternative specialist care is available.,

The Hospital in the Home Programme aims to prevent or substitute in-hospital care. It provides personal and clinical support and management of medical conditions, usually for medically stable patients who do not require a high level of clinical support. ${ }^{7}$ The care setting is usually the patient's own home or residential care facility. ${ }^{8}$ The programme provides a safe alternative for selected patients who require acute hospital-level care., ${ }^{910}$ The care cost of the programme is less than half of that of inpatient care, $^{11}$ and yet provides better patient and carer satisfaction. ${ }^{12-14}$

Since May 2015, the Bankstown-Lidcombe Hospital has introduced the Connecting Care Programme. We evaluated the programme's source of referral and immediate patient outcome, the impact on emergency department presentation, and the discharge rate from the emergency department (hospital admission avoidance).

\section{METHODS}

This study was approved by the Research and Ethics Committee at the South Western Sydney Local Health District Office in 2015 (LNR/15/ LPOOL/415). The Bankstown-Lidcombe Hospital is a principal referral hospital, with tertiary affiliations with the University of New South Wales, University of Sydney, and Western Sydney University. It has 454 beds and serves a population of $195,481 .{ }^{15,16}$ Its emergency department handles over 50,000 patients per year. ${ }^{17}$

Prior to May 2015, the hospital provided only non-urgent services for referrals from 16 nursing homes. Typical referrals were for management of behavioural and psychological symptoms of dementia, comprehensive geriatric assessment, and follow-up for certain complicated hospital discharges.

Since May 2015, in addition to non-urgent referral services, the hospital has provided acute geriatric services for urgent medical conditions (TABLE 1), except for emergency resuscitation and blood transfusion. Two consultant geriatricians share one full-time equivalent job, and a community
TABLE 1

Services provided by the Connecting Care Programme

\begin{tabular}{l}
\hline Services provided by the Connecting Care Programme \\
\hline Immediate and direct clinical review \\
Intravenous antibiotics \\
Intravenous and subcutaneous fluids \\
Bladder catheterisation \\
Delirium diagnosis and management \\
Anticoagulation \\
Fall prevention and management \\
Gastroenteritis outbreak management \\
Referral for radiology \\
Blood collection for the purpose of diagnosing acute illness \\
Acute pain management \\
Management of behavioural and psychological symptoms of \\
dementia (also provided previously) \\
End of life care \\
Staff education and training
\end{tabular}

nurse provides assistance to administer intravenous/ subcutaneous therapy. The Connecting Care Programme operates only during business hours (8:30 to 17:00), not in the evening or at weekends. The geriatricians can review the nursing home residents within 2 to 4 hours of referral, except when consent from patients and/or family is lacking.

Referrals were made to the geriatricians by direct phone calls from general practitioners, nursing home, and emergency department staff. Rarely, referrals also come from an inpatient medical team to facilitate early discharge. The geriatricians attend the emergency department every morning to identify patients who do not require admission and transfer them to the Connecting Care Programme. These patients will be discharged and then treated in the nursing home by a consultant geriatrician with follow up by a general practitioner. The programme does not offer post-emergency follow-up.

We compared the first 4 months (May to August 2015) of the programme with the same 4 months in 2014 to avoid possible seasonal variation in the emergency presentations. There were no other acute nursing home services or programmes at the same time in the Bankstown-Lidcombe Hospital. Activity of the programme was obtained from the geriatricians. Medical records of patients aged 65 years 
and older who presented during the study periods was obtained from the Emergency Department Data Manager, and those for nursing home residents were selected. Data from the emergency department were crosschecked with Connecting Care activity records.

Emergency department discharge diagnoses were classified as behavioural and psychological symptoms of dementia, respiratory illness, end-of-life care, urinary problem, cardiac illness, cerebrovascular/ seizure, fall with fracture, fall without fracture, cellulitis, dehydration, gastrointestinal illness, or other miscellaneous diagnoses included non-traumatic exacerbation of chronic pain, hyponatraemia, anticoagulation management, hyperglycaemia, and unwell with non-specific symptoms.

A patient was considered'admitted' to the hospital when an in-patient hospital bed was needed, and considered 'discharged' when an in-patient bed was not needed. For the purpose of this study, a patient who died in the emergency department was considered to have been 'admitted'. Emergency department presentation and discharge rates were calculated. Reasons for not returning to the nursing home after presentation to the emergency department were not examined.

The two groups were compared using the Student's $t$ test for continuous variables or the Pearson Chi-square test for categorical variables. All $p$ values were two-sided, and a $p$ value of $<0.05$ was considered statistically significant. No adjustment for multiple statistical testing was made.

\section{RESULTS}

Of the 175 cases referred to the Connecting Care Programme over the first 4 months (May to August 2015), 34\% were from general practitioners, 33\% from nursing homes, $26 \%$ from the emergency department, and $7 \%$ from in-patient wards. Of these, two were transferred to the emergency department for further management.

Respectively for the group before and after the programme, 4520 and 4475 presentations to the emergency department were by patients aged $\geq 65$ years. Of these, 276 and 318 involved nursing home residents (6.1\% vs $7.1 \%$, $\mathrm{p}=0.056$, TABLE 2). Of these, 106 and 167 were discharged from the emergency department ( $38.4 \%$ vs $52.5 \%$, odds ratio $=1.76,95 \%$ confidence interval=1.2-2.4, $\mathrm{p}=0.0008)$. Of the 167 nursing home residents discharged, 46 were assisted by the Connecting Care Programme.

The Connecting Care Programme increased the discharge rate in those with a diagnosis of fall without fracture $(70 \%$ vs $88 \%, \mathrm{p}=0.021)$, respiratory ( $11 \%$ vs $31 \%, p=0.020)$, gastrointestinal ( $34 \%$ vs $50 \%$, $\mathrm{p}=0.025)$, or cardiovascular ( $24 \%$ vs $60 \%, \mathrm{p}=0.010$ ) complaints (TABLE 2).

\section{DISCUSSION}

\section{Referral}

The Connecting Care Programme reduced the number of hospital admissions but not emergency presentations. Of 175 cases referred to the programme, $26 \%$ were by the emergency department and $74 \%$ were by general practitioners, nursing homes, or in-patient wards. The programme did not appear to have an impact on either emergency presentation or admission. The geriatricians in the programme also handle non-acute referrals. Some referrals were not strictly hospital avoidance, for example patients with behavioural and psychological symptoms of dementia. If a better referral pathway and triage system were in place and the programme could focus on acute referrals only, the results might have been different. Two of 175 patients were transferred to the emergency department for further care: one deteriorated beyond the capacity of the programme and another withdrew consent to be treated by the programme.

\section{Emergency presentation and hospitalisation}

Over the first 4 months of the programme, the percentage of emergency presentations by nursing home residents did not decrease. This may be because the programme operated only during business hours (8:30 to 17:00) and not at the weekend. The programme was new to the nearby nursing homes and was not widely publicised to the primary care services in the community. Health practitioners and nursing home residents and their families may lack confidence in the programme. Other likely factors associated with slow uptake of the programme include inadequate care planning, lack of advanced care planning, ${ }^{18}$ legal concerns, ${ }^{19}$ bureaucracy and conflicting stakeholder preferences. ${ }^{20,21}$ Nonetheless, the programme resulted in more nursing home 
TABLE 2

Discharge rates of nursing home residents from the emergency department before and after the Connecting Care Programme

\begin{tabular}{|c|c|c|c|c|c|c|}
\hline Variable & $\begin{array}{c}\text { May to } \\
\text { August } 2014\end{array}$ & $\begin{array}{c}\text { May to } \\
\text { August } 2015\end{array}$ & $\mathrm{p}$ Value & $\begin{array}{c}\text { May to } \\
\text { August 2014 } \\
(\mathrm{n}=276)\end{array}$ & $\begin{array}{c}\text { May to } \\
\text { August 2015 } \\
(\mathrm{n}=318)\end{array}$ & $\mathrm{p}$ Value \\
\hline $\begin{array}{l}\text { No. of presentations to emergency department by } \\
\text { patients aged } \geq 65 \text { years }\end{array}$ & 4520 & 4475 & - & - & - & - \\
\hline $\begin{array}{l}\text { No. (\%) of presentations to emergency department } \\
\text { by nursing home residents }\end{array}$ & $276(6.1)$ & $318(7.1)$ & 0.056 & - & - & - \\
\hline $\begin{array}{l}\text { No. (\%) of nursing home residents discharged from } \\
\text { emergency department }\end{array}$ & - & - & - & $106(38.4)$ & $167(52.5)$ & 0.0008 \\
\hline Mean $\pm S D$ age, $y$ & $85.6 \pm 7.4$ & $84.0 \pm 8.6$ & - & - & - & - \\
\hline Male:female ratio & $1: 1.22$ & $1: 1.19$ & - & - & - & - \\
\hline \multicolumn{7}{|l|}{ No. (\%) of discharges in those with a diagnosis of } \\
\hline Fall without fracture & $50(18)$ & $58(18)$ & 0.969 & $35(70)$ & $51(88)$ & 0.021 \\
\hline Respiratory & $45(16)$ & $45(14)$ & 0.465 & $5(11)$ & $14(31)$ & 0.020 \\
\hline Urinary/renal & $37(13)$ & $54(17)$ & 0.228 & $11(30)$ & $25(46)$ & 0.112 \\
\hline Gastrointestinal & $32(12)$ & $34(11)$ & 0.727 & $11(34)$ & $17(50)$ & 0.025 \\
\hline Cardiovascular & $25(9)$ & $25(8)$ & 0.600 & $6(24)$ & $15(60)$ & 0.010 \\
\hline $\begin{array}{l}\text { Behavioural and psychological symptoms of } \\
\text { dementia }\end{array}$ & $21(8)$ & $17(5)$ & 0.261 & $8(38)$ & $5(30)$ & 0.574 \\
\hline Cellulitis & $13(5)$ & $9(3)$ & 0.226 & $5(38)$ & $6(66)$ & 0.193 \\
\hline Fall with fracture & 9 (3) & $17(5)$ & 0.215 & $3(33)$ & $2(12)$ & 0.184 \\
\hline Stroke & 7 (3) & $10(3)$ & 0.657 & $2(29)$ & $3(30)$ & 0.949 \\
\hline Palliative & $0(0)$ & $4(1)$ & 0.062 & 0 & $4(100)$ & 1 \\
\hline Others & $37(13)$ & $45(14)$ & 0.793 & $20(54)$ & $25(56)$ & 0.891 \\
\hline
\end{tabular}

residents being discharged from the emergency department. Nursing home residents were $76 \%$ more likely to be discharged back to the nursing home, particularly those with a diagnosis of fall without fracture, respiratory, gastrointestinal, or cardiovascular complaints.

In a study in Austria, on-demand visits by geriatricians to nursing homes resulted in fewer hospitalisations (6.1 vs 11.7 per 100 residents, $\mathrm{p}<0.01) .{ }^{5}$ In another study, provision of a combined specialist nurse and physician service for nursing homes also resulted in fewer hospitalisations. ${ }^{6}$ In a Queensland study, the Hospital in the Home Programme resulted in significantly fewer emergency presentations (a rate ratio of 0.78 per 1000 nursing home beds) and hospitalisations (a rate ratio of 0.62 per 1000 nursing home beds), despite the programme not being exclusive to a consultant geriatrician..$^{22}$ In addition, a programme to enhance primary care has shown a $17 \%$ reduction in emergency presentations $(\mathrm{p}<0.001)^{23}$ and significant cost reduction in care provision. ${ }^{24}$ However, some studies have reported no or a non-significant reduction in emergency presentations or hospitalisations..$^{25-27}$

Our study involved only a single centre and did not evaluate nursing home residents who were referred to the ambulatory care unit for intravenous therapy or were admitted directly to a hospital ward. The aspects of bypassing emergency department were not studied. Nonetheless, these services were available in both 2014 and 2015. Furthermore, our study covered only 4 months. If the study was extended to an entire year, better seasonal representation of the impact of the Connecting Care Programme could be established to evaluate the need of the programme in less busy seasons such as spring or summer.

\section{Mortality and morbidity}

In a meta-analysis, treating nursing home residents in their familiar environment reduced mortality by $19 \%$, compared with hospital-based treatment. ${ }^{28}$ It 
is therefore a safe alternative for selected patients who require acute hospital-level care. ${ }^{10}$ In a randomised controlled trial of the Hospital in the Home Programme, home treatment reduced the incidence of delirium by $20 \%$, bowel complications by $22.5 \%$, and bladder complications by $14 \% .{ }^{29}$ In another study, the incidence of delirium was much lower in elderly people treated in their home rather than hospital (9\% vs 24\%). ${ }^{30}$ Furthermore, the use of antipsychotics is significantly lower if patients are treated in their own home. ${ }^{12}$

\section{Similar programme in other hospitals}

There are different types of programmes for nursing home residents in different hospitals. ${ }^{9}$ In the Sydney South-East area, the Geriatric Flying Squad has extended its hours of services to include evenings and weekends. Referrals can be seen by a specialist geriatrician or a nurse practitioner. Conditions managed by the Geriatric Flying Squad are delirium, cellulitis, urinary tract infection, anticoagulation, endof-life care, disease outbreak management (usually gastroenteritis), and acute pain management. ${ }^{31}$ In the Northern Hospital in Victoria, the Residential Care Intervention Programme for The Elderly (RECIPE) includes a geriatrician, geriatric trainee, and nursing staff with access to a full team of allied health practitioners. ${ }^{10}$ Both of these services are based on hospital avoidance / replacement care model. In contrast, the War Memorial Hospital provides assessment for functionally declining patients with a multidisciplinary approach to avoid emergency presentation and hospitalisation, but it does not provide acute medical treatment. ${ }^{32}$

Our Connecting Care Programme was operated by two part-time geriatricians with assistance from a community nurse, with no help from nursing or allied health staff. The community nurse assists in administration of intravenous fluids and medications. Currently, there is no triage system or referral pathway, and the geriatricians are the only point of contact. Upon seeing patients in the emergency department, the consultant geriatrician decides the appropriate management and suitability of the patient for discharge to the nursing home for treatment. This can potentially speed up the discharge process. The geriatrician can assess, diagnose, and formulate a management plan for complex and multifactorial geriatric syndromes..$^{33}$ In the case of palliative care support, the geriatrician can diagnose and treat comorbidities accordingly, rather than just administer palliative medications. The ability to prescribe medications to manage endof-life care enables higher efficiency and hence is cost saving. In Australia, nurse practitioners can prescribe medications within their area of expertise. The prescribing authority is conferred under the legislation of the state in which they practice. ${ }^{34}$ Although nurse practitioners can make clinically appropriate prescribing decisions, the cost of drugs prescribed by them is higher, and their assessment and diagnostic skills are lacking and they order more investigations than doctors. ${ }^{35}$ Each general practitioner provides palliative care to approximately 5 to 7 patients annually. ${ }^{36-38}$ Some general practitioners feel uncomfortable when confronting terminally ill patients. ${ }^{37}$ The palliative care training that they have received is insufficient. ${ }^{38-40}$ Time is one of the major constraints in the provision of adequate care to dying patients. ${ }^{38}$ Additional help to provide patients with palliative care is needed.

\section{CONCLUSION}

The Connecting Care Programme resulted in an increased discharge rate and decreased hospital admission rate for nursing home residents who presented with fall without fracture, respiratory, gastrointestinal, or cardiovascular complaints. The programme may enable better utilisation of healthcare resources.

\section{ACKNOWLEDGEMENT}

We would like to thank the invaluable comments from A/Prof Peter Smerdely, Geriatrician of St George Hospital, New South Wales, Australia.

\section{DECLARATION}

The authors have no conflicts of interest to disclose.

\section{REFERENCES}

1. Australian Institute of Health and Welfare. Authoritative information and statistics to promote better health and wellbeing (2016). Available from: www.aihw.gov.au/aged-care. Accessed 24 Feb 2016.

2. Wolfson C, Wolfson DB, Ashgharian M, et al. A reevaluation of the duration of survival after the onset of dementia. $N$ Eng J Med 2001;344:1111-6. Crossref

3. Briggs R, Coughlan T, Collins R, O'Neill D, Kennelly SP. Nursing home residents attending the emergency department: clinical 
characteristics and outcomes. QJM 2013;106:803-8. Crossref

4. Ouslander JG, Lamb G, Perloe M, et al. Potentially avoidable hospitalizations of nursing home residents: frequency, causes, and costs. J Am Geriatr Soc 2010;58:627-35. Crossref

5. Schippinger W, Hartinger G, Hierzer A, Osprian I, Bohnsting M, Pilgram EH. Mobile geriatric consultant services for rest homes. Study of the effects of consultations by internal medicine specialists in the medical care of rest home residents [in German] Z Gerontol Geriatr 2012;45:735-41. Crossref

6. Díaz-Gegúndez M1, Paluzie G, Sanz-Ballester C, Boada-Mejorana $\mathrm{M}$, Terré-Ohme S, Ruiz-Poza D. Evaluation of an intervention program in nursing homes to reduce hospital attendance [in Spanish]. Rev Esp Geriatr Gerontol 2011;46:261-4. Crossref

7. New South Wales Health. Hospital in the Home Guidelines. 2013. Available from http://www.health.nsw.gov.au/policies/gl/2013/ pdf/GL2013_006.pdf. Accessed 14 Feb 2016.

8. CHERE. Consultancy to Progress Hospital in the Home care provision: Final report. Commonwealth of Australia 1999. ISBN 064241558 7.

9. Hospital in the Home Society. Submission to the National Health and Hospitals Reform Commission. Available from http://www.health.gov.au/internet/nhhrc/publishing.nsf/ Content $/ 451 / \$ F I L E / 451 \% 20-\% 20$ SUBMISSION $\% 20-\% 20$ Hospital\%20in \% 20the $\% 20$ Home $\% 20$ Society $\% 20$ NSW.pdf. Accessed 15 Feb 2016.

10. Lau L, Chong CP, Lim WK. Hospital treatment in residential care facilities is a viable alternative to hospital admission for selected patients. Geriatr Gerontol Int 2013;13:378-83. Crossref

11. Board N, Brennan N, Caplan GA. A randomised controlled trial of the costs of hospital as compared with hospital in the home for acute medical patients. Aust N Z J Public Health 2000;24:30511. Crossref

12. TibaldiV, Aimonino N, Ponzetto M, et al.A randomized controlled trial of a home hospital intervention for frail elderly demented patients: behavioral disturbances and caregiver's stress. Arch Gerontol Geriatr Suppl 2004;9:431-6. Crossref

13. Caplan GA, Coconis J, Board N, Sayers A, Woods J. Does home treatment affect delirium? A randomised controlled trial of rehabilitation of elderly and care at home or usual treatment (The REACH-OUT trial). Age Ageing 2006;35:53-60. Crossref

14. Leff B, Burton L, Mader SL, et al. Hospital at home: feasibility and outcomes of a program to provide hospital-level care at home for acutely ill older patients. Ann Intern Med 2005;143:798-808. Crossref

15. South Western Sydney Local Health District- Bankstown Hospital. About Us. 2014. Available from http://www.swslhd.nsw. gov.au/bankstown/about.html. Accessed 22 October 2015.

16. Bankstown City Council. Welcome to Bankstown City Community Profile. Available from http://profile.id.com.au/bankstown. Accessed 22 Oct 2015.

17. Bureau of Health Information. Bankstown / Lidcombe Hospital: Emergency department (ED) overview. 2015. Available from: http://www.bhi.nsw.gov.au/publications/hospital_quarterly_ $n s w / ? a=281602$. Accessed 22 October 2015

18. Nair B, Kerridge I, Dobson A, McPhee J, Saul P. Advance care planning in residential care. Aust N Z J Med 2000;30:33943. Crossref

19. Tonti-Filippini N. Neglected to death - is this the Howard government's aged care philosophy? 2004. Available from: www. onlineopinion.com.au/view.asp? article=2208. Accessed 20 Jan 2016.

20. Arendts G, Quine S, Howard K. Decision to transfer to an emergency department from residential aged care: a systematic review of qualitative research. Geriatr Gerontol Int 2013;13:82533. Crossref

21. Arendts G, Reibel T, Codde J, Frankel J. Can transfers from residential aged care facilities to the emergency department be avoided through improved primary care services? Data from qualitative interviews. Australas J Ageing 2010;29:61-5. Crossref

22. Fan L, Hou XY, Zhao J, et al. Hospital in the Nursing Home program reduces emergency department presentations and hospital admissions from residential aged care facilities in Queensland, Australia: a quasi-experimental study. BMC Health Serv Res 2016;16:46. Crossref

23. Codde J, Arendts G, Frankel J, et al. Transfers from residential aged care facilities to the emergency department are reduced through improved primary care services: an intervention study. Australas J Ageing 2010;29:150-4. Crossref

24. Burl JB, Bonner A, Rao M, Khan AM. Geriatric nurse practitioners in long-term care: demonstration of effectiveness in managed care. J Am Geriatr Soc 1998;46:506-10. Crossref

25. Kane RL, Garrard J, Skay CL, et al. Effects of a geriatric nurse practitioner on process and outcome of nursing home care. Am J Public Health 1989;79:1271-7. Crossref

26. Kane RL, Garrard J, Buchanan JL, Rosenfeld A, Skay C, McDermott S. Improving primary care in nursing homes. J Am Geriatr Soc 1991;39:359-67. Crossref

27. Aigner MJ, Drew S, Phipps J. A comparative study of nursing home resident outcomes between care provided by nurse practitioners/physicians versus physicians only. J Am Med Dir Assoc 2004;5:16-23. Crossref

28. Caplan GA, Sulaiman NS, Mangin DA, Aimonino Ricauda N, Wilson AD, Barclay L. A meta-analysis of "hospital in the home". Med J Aust 2012;197:512-9. Crossref

29. Caplan GA, Ward JA, Brennan NJ, Coconis J, Board N, Brown A. Hospital in the home: a randomised controlled trial. Med J Aust 1999; 170:156-60.

30. Leff B, Burton L, Mader SL, et al. Hospital at home: feasibility and outcomes of a program to provide hospital-level care at home for acutely ill older patients. Ann Intern Med 2005;143:798-808. Crossref

31. Gonski P, Jain S, Wedell N, Patras A, Collins N. Southcare Geriatric Flying Squad-Initiative to Improve Quality of Care in Aged Care Facilities: Local Solutions. NSW Health: South Eastern Sydney Local Health District. 2013. Available from: http://www.Health. nsw.gov.au/innovation/2013awards/Documents/southcareGeriatric-flying-squad-web-11.pdf. Accessed 20 Jan 2016.

32. War Memorial Hospital. Geriatric Flying Squad. Rapid Assessment for the Functionally Declining Patient. Available from: http://www. wmhw.org.au/index.php?id=37. Accessed 28 Feb 2016.

33. Obeid J. Definition of a geriatrician. Australian and New Zealand Society for Geriatric Medicine; Available from: http://www. anzsgm.org/posstate.asp. Accessed 28 Feb 2016.

34. Safety and quality guidelines for nurse practitioners. Australian Nursing and Midwifery Board of Australia. Available from: http:// www.nursingmidwiferyboard.gov.au. Accessed 28 Feb 2016.

35. Latter S, Smith A, Blenkinsopp A, Nicholls P, Little P, Chapman $\mathrm{S}$. Are nurse and pharmacist independent prescribers making clinically appropriate prescribing decisions? An analysis of consultations. J Health Serv Res Policy 2012;17:149-56. Crossref

36. Wakefield MA, Beilby J, Ashby MA. General practitioners and palliative care. Palliat Med 1993;7:117-26. Crossref

37. Mitchell GK. How well do general practitioners deliver palliative care? A systematic review. Palliat Med 2002;16:457-64. Crossref

38. Reymond E, Mitchell G, McGrath B, Welch D. Research into the educational, training and support needs of general practitioners in palliative care. Report to the Department of Health and Ageing. Brisbane: Mt Olivet Health Services, 2003. Available from: http:// www.mtolivet.org.au/Research/Research\%20Projects/Research_ projects.htm. Accessed 28 Feb 2016.

39. Barclay S, Todd C, Grande G, Lipscombe J. How common is medical training in palliative care? A postal survey of general practitioners. Br J Gen Pract 1997;47:800-4.

40. Charlton R, Ford E. Education needs in palliative care. Fam Pract 1995;12:70-4. Crossref 